\title{
Attitudes to Sexism and Gender Equity at
a Danish University
}

BY Lea Skewes, Joshua C. Skewes, and Michelle K. Ryan

\section{ABSTRACT}

We designed this study to measure the degree of backlash a specific Danish university would encounter in response to gender equity interventions. To capture this resistance we used two standardized questionnaires: the Modern Sexism Scale, which measures explicit denial of gender discrimination and resentment towards gender equity demands (such as gender interventions) and the Support for Discriminatory Practices which measures peoples explicit preferences for hiring men over women. We also asked an open question about attitudes towards the university's current gender policies. The questionnaire was sent to 15,493 employees. With one prompt 1,805 completed the entire questionnaire. We found that university employees scored above the midpoint on modern sexism, indicating that, on average, they held sexist attitudes. We further showed that modern sexism scores varied depending on beliefs about what was being done for gender equity in the organization, such that those who thought that enough or too much was being done had significantly higher sexism scores than those who thought that not enough was being done. Over all, our findings document explicit sexist attitudes within the target university and suggest that gender equity interventions are therefore likely to be met by great resistance from some.

\section{KeYWORDS}

Explicit attitudes, sexist attitudes, gender discrimination, modern sexism, support for discriminatory practices, gender equity

Lea Skewes, Post-Doctoral Researcher, Gender Studies (Tema Genus), Linköping University, Sweden. Joshua C. Skewes, Associate Professor, Aarhus University, Denmark.

Michelle K. Ryan, Professor of Social and Organisational Psychology, University of Exeter, UK, and Professor of Diversity, University of Groningen, The Netherlands. 


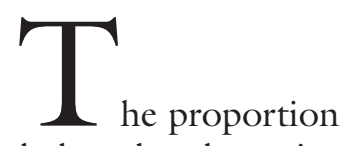

of women in the workplace has been increasing steadily for most Western countries since the 1950's (Rudman and Glick 2018; Ministry of Employment in DK 2010). In terms of labor market participation some countries are starting to approach parity between genders, with Scandinavian countries providing a well-known example of this trend. In 2010, the Danish Ministry of Employment reported that Denmark had one of the highest employment rates for women in the EU, with $74.4 \%$ of working age women in employment, compared to $79.2 \%$ of men (Ministry of Employment in DK 2010).

In addition to an overall increase in labor market participation, there has also been an increase in gender integration in the workplace. Women are now more likely to find employment in historically male dominated fields, and are more likely to hold positions of authority that have formerly been held by men (Huffman, Cohen and Pearlman 2010). However, the trend towards increased integration has been less pronounced than the trend toward increased labor market participation. In fact, there is a clear tendency for women to find employment in lower status and lower paying occupational roles (Charles and Grusky 2004). The purpose of the present study is to attempt to identify possible factors which might contribute to gender segregation in academia.

Earlier studies (Henningsen and Højgaard 2002) have documented that it is not primarily a lack of women seeking jobs in academia that is holding Denmark back from achieving gender equity, but rather gender biases in funding and hiring practices. Building upon these findings, we investigated possible social psychological factors with the potential to limit the effectiveness of current gender equity policy in academia. A particular university supported this study, financially and practically, to improve knowledge about the organization's gender equity challenges and to shape the gender equity policies going forward. We carried out this study because even though the university had explicit policies aimed at improving awareness of gender in hiring and promotion there still was a clear pattern of gender segregation with women being overrepresented in administrative positions, while being under-represented in full time and senior research positions. At the particular university gender representation is approximately equal for trainee positions, with women making up 52.3\% of PhD students. Women are slightly under-represented in temporary and tenure track positions, holding $42.9 \%$ of postdoctoral research positions, and $42.2 \%$ of assistant professorships. Women are more clearly under-represented in permanent and senior research positions, holding only $36.1 \%$ of associate professorships and $22.1 \%$ of full professorships across the university. At one faculty, women are severely under-represented, holding only $9.9 \%$ of full professorships.

In addition to being male dominated particularly in STEM fields (Henningsen and Højgaard 2002; Moss-Racusin et al. 2012), studies have demonstrated that research occupations are more strongly linked to masculine stereotypes than feminine stereotypes (Carli et al. 2016). Acker's (2006) research in Swedish banks - another male dominated field - confirmed that some organizations are fundamentally male gendered. Other researchers find that our perception of fit between gender and occupational stereotypes is key for our assessment of success in the workplace. For example, Heilman (1983) has documented how a perceived misfit contributes to discriminatory practices against women in the form of poorer evaluations and lowered expectations of success, which lead to lower 
chance of promotions compare to equally qualified male coworkers.

While Heilman's lack of fit model illustrates that implicit gender stereotypical expectations lead to gender discriminatory practices in the workplace $(1983 ; 2012)$, more explicit gender dynamics might also limit the effectiveness of organizational gender equity policy. The Modern Sexism scale was chosen for this study because it captures sexist ideology, which is known to correlate with a tendency to opposition to policies or changes designed to increase gender equity (Sibley and Perry 2010; Swim et al. 1995). Modern sexism captures the belief that inequality between genders no longer exists (Swim et al. 1995). People who subscribe to modern sexism underestimates the degree to which gender leads to discrimination, and often fail to recognize gender discrimination when it takes place (Swim et al. 1995; Swim, Mallett, and Stangor 2004).

What can a high score on the Modern Sexism scale tell us about the work environment in an organization? The modern sexism scale captures one type of resistances to the changes in gender stereotypical roles. Sakalli-Ugurlu (2009), like Swim and colleagues (1995), found that people who support sexist ideologies, measured by the modern sexism scale, showed less support for women in high-status educational or occupational domains. Sibley and Perry (2010) found a correlation between sexist ideologies and policies designed to attenuate male dominance. Furthermore, research demonstrates that men typically have higher modern sexism scores than women (Cambell, Schellenberg and Senn 1997; Swim et al. 1995), with rare exceptions (Van Wijk 2011).

Individuals who scored high on modern sexism are also more likely to attribute sexsegregation in the workplace to individualistic or biological causes rather than discrimination or prejudice against women (Swim et al. 1995). Indeed, Swim et al. (2004) found that people who scored high on modern sexism were more likely to use sexist language, but that they did not consider it sexist language - in other words they were blind to their own sexist behavior. Becker and Swim (2011) demonstrate that women and men need to acknowledge different aspects of workplace sexism in order to change it. They showed that for women it was sufficient to increase their awareness of the problem, by letting people take daily diaries of the sexism they were exposed to. However, for men awareness of the problem was not a sufficient motivator to change sexist behavior, an additional dimension of emotional empathy for the target of discrimination was necessary.

Another dimension of sexism that is positively correlated with modern sexism is Glick and Fiske's (2001) notion of hostile sexism, described as an antipathy toward women who challenge men's power and status by taking on men's stereotypical roles. There is a strong correlation between hostile sexism and modern sexism, suggesting that modern sexism reflects more hostile sexist attitudes towards women than benevolent attitudes (Glick and Fiske 1996; 1997). In this context, hostile sexism taps into the questions of whether attitudes to women in male-typed jobs have caught up with the reality that many Danish women have chosen to move into male-typed jobs such as academia.

We chose to include the Support for Discriminatory Practices scale (Morton et al. 2009), for two reasons. First, the university was particularly interested in increasing the number of women in higher ranking academic positions. It would therefore be of interest whether this goal is hindered by explicit hiring preferences amongst their employees. Second, Skewes, Fine and Haslam (2018) had previously carried out a largescale study using the Support for Discriminatory Practices Scale on a representative (on gender, age, geography, and education) Danish sample which could offer an interesting comparison. 
Concretely, we explored resistance and support of the policies at a particular university. We expected a positive correlation between high modern sexism scores, high support for discriminatory practices scores, and verbal expressions against increased gender equity. This is because modern sexism is a form of explicit bias which promotes the unequal treatment of women, which gender equity interventions are intended to prevent.

\section{PARTICIPANTS}

The sampling frame for the study was student assistants, researchers, and administrative staff under active employment at the university. Cleaning staff, maintenance staff, and external contractors were not recruited for the study. Both administrative and academic staff were included because we assumed they both contribute to setting the everyday tone of the work environment in the organization. In total, 15493 members of staff were invited to participate. 2183 employees responded to at least one question on the survey. Participant demographics are included in Table 1.

From the full sample, 1805 participants completed the questionnaire. Not all provided full responses to all questions. Responses from incomplete questionnaires were included in the analysis wherever possible. This was done to minimize bias caused by differential drop-out, and to maximize the representativeness of the sample relative to the sampling frame. Responses to the survey scale items were included in analyses only if scales were completed in full. This was done to ensure that the reliability and interpretation of the scale scores was consistent with published literature.

\section{Procedure}

In June 2018, the university employees were invited to respond to an online ques- tionnaire on attitudes towards policy changes in the organization. It was stated that the intention of the questionnaire was to contribute to future policy initiative in the organization, but it was not specified that these concerned gender specifically. Being non-specific about the focus on gender was intended to reduce the risk of sampling bias (i.e., to avoid selectively recruiting individuals with strong opinions about gender policy). The questionnaire was distributed by an external polling company (YouGov) to all employees via their company email addresses. Using an external polling company ensured participant anonymity, and made it possible to anonymize the results before the researchers gained access to the data. Participants were given the option of responding to the questionnaire either in Danish or in English.

Participants were first asked to complete four demographics questions. They were asked to state their gender, their age range, their job function, and the faculty they were associated with. They were then asked to complete two standardized surveys: the Modern Sexism scale (Swim et al. 1995), followed by the Support for Discriminatory Practices scale (Morton et al. 2009). Participants were then asked to provide their opinion on university's gender equity policy, and to provide their opinion on the \#MeToo movement. Responses to the last question are beyond the scope of the present article and are not analyzed or reported here.

\section{Materials}

The Modern Sexism scale (Swim et al. $1995)$ is an eight-item inventory used to measure individuals' denial of gender discrimination, and their resentment and antagonism towards gender equality demands. In the current questionnaire, each item on the scale was answered on a 7 point Likert scale (from 1 = completely disagree to $7=$ completely agree), such that 
Table 1: Participant demographics

\section{Gender}

Female

Male

Other

Prefer not to answer

Did not answer

Age

$18-27$

28-37

$68+$

Prefer not to answer

Did not answer

Job function

Scientific position

Administrative position

Other position

Prefer not to answer

Did not answer

Academic rank among scientific staff

Student assistant

Research assistant

External lecturer

PhD student

Post.Doc

Assistant Professor

Associate Professor

Full Professor

\section{Role among technical/administrative staff}

Administrative staff with no academic degree (HK)

Administrative staff with no academic degree $(\mathrm{HK})$ and managerial responsibility $\quad 163$

Administrative staff with an academic degree (AC)

Administrative staff with an academic degree (AC) and managerial responsibility

\section{Research/Educational areas}

Science

Social science

Health and Medicine

Liberal Arts and Humanities

Other 
any score above 3.5 indicates an agreement with sexist statements. Individual scale scores were computed by averaging the Likert scores for each of the items, after accounting for reverse scoring. The Modern Sexism scale has previously been shown to have questionable (e.g. alpha $=.65$; Campbell et al. 1997) to acceptable reliability (e.g. alpha $=.79$; Morrison, Morrison, Pope and Zumbo 1999). However, the reliability of the scale for the current sample was $\operatorname{good}($ alpha $=.89)$.

The Support for Discriminatory Practices scale (Morton et al. 2009) is a fouritem scale used to assess support for gender discrimination in hiring practices. In the current questionnaire, each item on the scale was answered on a 7-point Likert scale (from 1 = completely disagree to $7=$ completely agree). Individual scale scores were computed by averaging across the items, after accounting for reverse scoring. The scale has previously been shown to have acceptable (e.g. alpha $=.75$; Morton et al. 2009) to good reliability (e.g. alpha $=$ .83; Skewes et al. 2018). The reliability of the scale for the current sample was poor, however $($ alpha $=.47)$. The reliability problem in our sample was most likely caused by the fact that we adapted the language of this scale to capture a university setting, rather than preserve the more general language of the original scale. Unfortunately, this reliability score means that the results for this otherwise reliable scale are not readily interpretable in the current context.

The question "What do you think of this organization's gender equity policy" was presented as a separate item. This question was posed because it was key to the study to uncover whether people were supportive, neutral, or against the organization's current gender equity policy, and whether these attitudes were related to modern sexism and support for discriminatory practices. Participants were able to respond, "I don't know what this organizations gender equity policy is"; “I don't have an opinion on this organization's gender policy"; "Prefer not to answer"; or to provide an open answer response.

\section{DATA ANALYSIS}

Individual level scores were calculated for the Modern Sexism and Support for Discriminatory Practices scales as described in the materials subsection.

Open answer responses to the question "What do you think of this organizations gender equity policy" were analyzed by the first author using a Grounded Theory approach (Glaser and Strauss 1967; Strauss and Corbin 1990). Two coding iterations were completed. The first iteration focused on explicit attitudes concerning the effectiveness of the organization's current gender policy. Responses were initially coded as reflecting either the attitude that not enough was being done in the organization to achieve gender equality, or the attitude that enough was being done. During the coding process, however, it became apparent that a third category was also present in the responses, reflecting the attitude that too much had been done to achieve equity, and that men were now being discriminated against. Responses were then recoded with the inclusion of this third category.

The second coding iteration was used to explore whether any reoccurring themes emerged in the open answers. Five themes arose from this analysis. In order of prominence, these were (1) a lack of implementation of the existing gender equity policy, (2) expressions of gender blindness, (3) assumed reverse discrimination, (4) critiques of concrete policies, and (5) backlash against the questionnaire. These themes were analyzed in relation to the three primary qualitative categories described above.

Qualitatively defined attitudes to the organization's gender equity policy were then related to individual modern sexism and support for discriminatory practices scores, 
using a multinomial logistic regression model. The model included scale scores as predictors, and attitude to the policy as an outcome. In this way, we used individual modern sexism and support for discriminatory practices scores to predict the relative probability that participants held the attitude that too little, enough, or too much was being done at the organization to address gender equity. This was done to explore the relationship between explicit sexism on the one hand, and attitudes to the organization's gender equity policy on the other, with the specific aim of determining whether sexism may function as a barrier to acceptance and implementation of the policy.

\section{QUESTIONNAIRE RESPONSES AND SCALE SCORES}

From the sample 1488 participants (729 men and 749 women) provided answers for all items in the modern sexism scale $(\mathrm{M}=$ $4.18, S D=1.34)$ and 1691 participants (823 men and 849 women) provided answers for all items in the support for discriminatory practices scale $(\mathrm{M}=1.55, S D=$ $.76)$. The scales were significantly negatively correlated $(r=-.19, p<.001)$. From the policy question $43.84 \%$ of the total sample reported not knowing about the organization's gender equity policy, $13.00 \%$ reported not having an opinion on the policy, $6.14 \%$ preferred not to answer, $16.90 \%$ did not provide a response, and $20.11 \%$ provided an open answer response.

Employees' average modern sexism scores of 4.18 (on a 7-point Likert scale) places them above previous scores found in the literature, indicating challenges with sexist attitudes. To compare, Swim and colleagues' (1995) original study on US psychology students found a mean score ranging between 1.93-2.68 (on a 5-point Likert scale) suggesting disagreement with the majority of the statements. In Ekehammer, Akrami and Araya's (2000) more compara- ble Swedish study, they found a score on the MS ranging from 1.87-3.34 on the individual items on a 5 -point Likert scale, and a mean of $2.28(S D=0.75)$.

Modern sexism scores were significantly higher for men $(M=4.59, S D=1.32)$ than women $(M=3.79, S D=1.22)[t(1455.1)$ $=12.04, p<.001]$. However, support for discriminatory practices scores were similar for men $(M=1.53, S D=.75)$ and women $(M=1.57, S D=.77)[t(1669.9)=1.10, p$ $<.27]$. There was a significant association between gender and responses to the question about gender policy $\left(\mathrm{Chi}^{2}(9)=63.65\right.$, $\mathrm{p}<.001)$, such that more women (518) than men (433) reported not knowing the university's gender equity policy. More men (179) than women (104) reported not having an opinion about the policy. More women (222) than men (206) gave open responses. Slightly more women (65) than men (60) declined to respond to the policy question.

\section{QuALitaTive ANALySES OF \\ ATTITUDES TO GENDER POLICY}

Of the open responses, 49 were off topic, or could not otherwise be categorized as expressing an attitude with regard to the policy, leaving 390 meaningfully responses. Remaining responses were categorized exclusively and exhaustively as expressing one of the following three attitudes: (1) that the policy contributes nothing or too little to gender equity in the organization; (2) that the policy contributes the right amount to gender equity; or (3) that the policy did too much for women at the expense of men.

The words used most frequently in the nothing or too little category were ineffective (6), insufficient (5), unambitious (3), and a catastrophe (2). Other terms used to describe the policy were: unprofessional, underdeveloped, inadequate, superficial, vague, weak, short-sighted, statement-like, dreadful, empty air, invisible, absent, slack, unfocused, embarrassing, shameful, lousy, 
and purely symbolic. Of the open answers, most $(54.36 \%)$ expressed the attitude that the policy contributes nothing or too little to equity $\left(\mathrm{Chi}^{2}(2)=110.14, \mathrm{p}<.001\right)$. This attitude is exemplified in the following quote:

\section{"Are there any [gender equity policies]? Dur- ing my time here (...) I have seen several posi- tions being filled and NEVER EVER has the question of gender come up. On the contrary, I know of departments that have done everything they could NOT to hire women. It s very dis- graceful and [the university]/Denmark need to do more." Male, Associate Professor.}

The words used most frequently of the right amount category were okay (32), fine (25), good (17), sensible (11), well-balanced (5), and appropriate (3). 34.62\% expressed the attitude that the policy contributes to equity in the right amount. This attitude is exemplified in the following quote:

"I sense that [the university] employs the best candidate in all positions. I think that is a great policy." Female, administrative position.

The words used most frequently in the too much category were favoritism (of women), preferential treatment (of women), and reverse discrimination (against men). 11.03\% expressed this attitude exemplified in the following quotes:

"Consider it hysterical to focus so much on 50\%/50\% in hiring/committees/appointments etc. - instead of looking at the individual qualifications. Gender equality is about to tip over." Male, Associate Professor.

\footnotetext{
"I simply do not understand the need for [the university] to have a specific action plan for more women in research. Should we not then also introduce actions plans for transsexuals in research etc.? The plan is in and of itself discriminatory.” Male, Associate Professor.
}

RELATING QUALITATIVE

\section{CATEGORIZATION OF ATTITUDES}

TO SCALE SCORES

There were mean differences for Modern Sexism scale scores across the different categories, Too Little, $\mathrm{M}=3.04(S D=1.20)$, Right Amount, $\mathrm{M}=4.74(S D=1.15)$, and Too Much $\mathrm{M}=5.82(S D=1.09)$. Support for Discriminatory Practices scale also varied by attitudes to gender policy: Too Little, $\mathrm{M}=1.75$ (SD = .78), Right Amount, $\mathrm{M}=$ $1.38(S D=.59)$, and Too Much, $\mathrm{M}=1.48$ $(S D=.72)$.

Mean Modern Sexism and Support for Discriminatory Practices scores were formally related to attitudes towards the policy's effectiveness using a multinomial logistic regression model. The model was built to predict how likely participants are to express one of the three attitudes characterized in the qualitative analysis.

Results from the the model (Table 2) suggest that support for discriminatory practices is not significantly related to gender policy attitudes. However, the model suggests that modern sexism is significantly related to attitudes towards the policy, such that for every point increase in modern sexism, participants are more likely to believe that the policy does too much in favor of women.

\section{QUALITATIVE IDENTIFICATION OF OTHER RECURRING THEMES IN OPEN RESPONSES TO THE POLICY QUESTION}

The three most prominent themes in the gender equity answer were: (1) a lack of connection between policies and implementation, (2) assumed gender blindness, and (3) assumed reverse discrimination.

\section{Gender Equity Policies $\neq$ IMPLEMENTATION}

The most common recurring theme in the open comments on gender equity was that 
Table 2: The results of a multinomial logistic regression model built to test the relationship between the scale scores and qualitatively identified attitudes. The model includes MS and SDP as predictors. The model includes attitude to the policy as the outcome, with the reference value for the outcome set at the "Enough" attitude category. The model is implemented in the R language, using the nnet package (Venables and Ripley 2002). Coefficients represented are the exponentiated values of the logit coefficients.

Too Little

Modern Sexism

Support for Discriminatory Practices

Constant

Akaike Inf. Crit.

Note:
$0.354^{* * *}$

$(0.130)$

1.302

(0.224)

$49.558^{* * *}$

$(0.690)$

455.979

${ }^{*} \mathrm{p}<0.1 ;{ }^{*} \mathrm{p}<0.05 ;{ }^{* *} \mathrm{p}<0.01$
Too Much

$2.276^{* * *}$

1.613

(0.327)

$0.002^{* * *}$

(1.361)

455.979 there appeared to be no actions driven by the policies. Ninety-four out of 390 people brought this theme up. For example:

"I think [the gender equity policy] has not been enacted. I think it is a sheet of paper that has no weight or effect because there's no implementation and no accountability." Female, Other.

"The nicest thing you can say about it [the gender equity policy] is that it exists. As far as I know there is nobody who really uses it for anything." Male, AC with managerial responsibilities.

"Lacking and ineffectively communicated. Looks more like "now we have a policy and a checklist" than an actual action plan and a goal. Why is there no; homepage, discussion forum, practical information, discussion material, employee meetings, student initiatives?" Male, Professor.
A sub-category of this group who questioned the implementation of the gender policies (14) express explicit distrust in whether the leadership at the university intended the gender equity policy to be more than window dressing. This opinion was expressed as follows:

"The leadership says a lot of politically correct words about gender equality but they do not mean it." Male, Associate Professor.

"The gender equity policy] is primarily an expression of good intentions that so far has had no greater practical consequences. One often is left with the impression that the policy is not intended to be taken seriously." Female, Professor.

This group of people who challenge whether the gender equity policies are in fact being implemented almost exclusively 
(93/94) belong to the category of employees who believe that not enough is being done to achieve gender equity at the university. Of this group, 67 were female, 22 were male, one reported their gender as "other", and four declined to report their gender $\left(\mathrm{Chi}^{2}(3)=75.8, \mathrm{p}<.001\right)$.

\section{Gender BLindness}

The second most reoccurring theme was a belief that gender blindness in hiring and/or interactions either had already been achieved, or was achievable without any form of interventions or tools. Forty-one out of 390 people expressed such an opinion. For example:

\section{"People should be hired on the basis of their abilities, not on the basis of their genitalia. If more men than women are capable of a certain position, and thus more men are hired, then so be it." Male, Post-Doctoral Researcher.}

"Gender should not play a role in meritocratic society, in other words academic policy shall hire the best person for the job and gender should be meaningless." Male, PhD fellow.

Gender blindness is one of the key factors measured with the Modern Sexism scale, thus as one might expect modern sexism scores were significantly higher for this subgroup $(M=5.22, S D=1.31)$ than for the remainder of the sample $(M=4.15, S D=$ $1.33)[t(34.61)=4.69, \mathrm{p}<.001]$. Of this group, 12 were female, and 29 were male $\left(\mathrm{Chi}^{2}(\mathrm{l})=7.05, \mathrm{p}<.008\right)$.

\section{REVERSE DISCRIMINATION}

The third most common theme was a belief that the gender equity policies had been too "effective" so that they in fact had created reverse discrimination against men - in other words, mediocre women were perceived to be hired at the expense of better qualified men. Twenty-nine people held this opinion. A few examples captures this opinion:

"Unacceptable and blind favoring of women. Merit plays less and less role, regrettably. Feminist ideology is taking over this place. (...) Forceful equalization of men's and women's outcomes happens only at the expense of men." Male, Research Assistant.

"The requirement to bire a certain amount of women runs contrary to this [hiring on the basis of merits] and ends up putting the wellqualified women in a bad light. I have not observed any institutional or cultural obstacles for women, on the contrary; our education system is rather feminized which also is reflected in our gender distribution amongst university employees. I consider the gender inequality in the higher ranking positions a result of the fact that more men than women, for better or worse, are ready to make greater sacrifices, for instance on the family front, in the hunt for career options." Male, Associate Professor.

Such statements align themselves with high modern sexism scores because they express a denial of an unfair gender segregation in the workplace. But these attitudes also align quite well with hostile sexism in that gender equity measures are considered to create an unfair advantage for women. Modern sexism scores were significantly higher for this sub-group $(M$ $=5.97, S D=1.03)$ than for the remainder of the sample $(M=4.15, S D=1.32)$ $[t(25.39)=8.75, \quad \mathrm{p}<.001]$. Of this group, 3 were female, and 25 were male, and one declined to report their gender $\left(\mathrm{Chi}^{2}(2)=36.69, \mathrm{p}<.001\right)$.

\section{CRITIQUES OF SPECIFIC POLICIES}

Another theme to emerge was explicit comments or critiques of current university policies. The three most critiqued policies were, (1) a requirement to stay abroad, (2) a lack of female leaders (particularly at the 
very top), and (3) the need to distribute the costs for maternity leave better.

\section{REQUIREMENT TO STAY ABROAD}

Twenty-three out of 390 people perceived the university requirement to stay abroad as a gender biased policy which conflicted with the goal of more women in research. For example:

"I perceive it is a great gender equality problem that we are only meant to hire people who have been employed abroad for tenure track positions (...). In other words, there are other policies that conflict with the gender equity policies." Female, Assistant Professor.

\section{THE NEED FOR FEMALE LEADERS}

The second most mentioned policy challenge at the university was a need for more women in senior leadership positions. Twenty people stated more women were needed in high leadership positions:

"I think the university should do more to ensure the hiring of women, particularly in leadership positions." Female, AC.

\section{REQUEST FOR A FINANCIAL SOLUTION} TO THE BURDEN OF MATERNITY LEAVE

Finally, employees requested solutions that distributed the expenses associated with maternity leave more fairly, to lift the financial burden of the immediate work environment on to the university as a whole because of the asymmetrical gender distribution between faculties. Fourteen people expressed this opinion:

"[The university] has some fine guidelines [for gender equity]. However, when suggestions like the supported maternity leave fund gets put forward then they do not want to support it after all." Male, Professor.

\section{BACKLASH AGAINST}

THE QUESTIONNAIRE

Finally, 14 out of 390 people voiced a critique of the questionnaire itself. Two of the people in this group expressed problems with the questionnaire as not being progressive enough. One commented on how the choice to run this survey was intertwined with the problems of the organization $s$ gender equity policies:

"[The gender equity policies are] unprofessional and underdeveloped. Too few initiatives where central leadership people (also male ones) play a key role and take ownership of the policy. Too many decentralized initiatives as this one [questionnaire] where one outsources the gender equity work to female employees, junior researchers, and ad hoc initiatives." Female, Associate Professor.

The majority (9) of people in this group, however, rejected the questionnaire as unprofessional or ill designed. A professor who preferred not to note their gender or faculty writes:

"[Y]our questionnaire is NOT neutral: it is like you composed it to confirm your prejudice or to press buttons in your audience. You need to consult a statistician and a data analyst.”

"Your questions are infantile and ridiculous." Male, Associate Professor.

A male PhD fellow even goes as far as to claim that the survey itself is an expression of discrimination because of its focus on women:

\section{"There can also be women who are preferred over men. Therefore, I consider this question- naire discriminatory against men. My sex $H A S$ challenges when it comes to being deselect- ed instead of women."}

This type of response is particularly interesting because the questionnaire was de- 
signed to detect potential backlash against gender equity interventions, and these responses suggest that even collecting data on the topic of gender is perceived as controversial and unfair by some employees in the organization.

\section{Discussion}

In Acker's (2006) classical work "Inequality Regimes" she brings home the banal, yet key point, that in order to change organizational structures one has to be able to see the problem and consider it a problem worth solving. In other words, the problem which in this case is gender inequality needs to be highly visible and considered an illegitimate state of affairs. In this organization the opposite state seems to be the case; gender equity is not visible to the average employee and status quo is considered to be fairly achieved by many. Elaborating on this point, in spite of the originally gender progressive intentions expressed in both the call which funded this study and the action plan of this organization, almost $44 \%$ of the employees admitted that they did not know the organization's gender equity policies. This implies at the very least that communication about gender equity goals have not been successfully disseminated. This is particularly important in the light of Acker's (2006) point about the importance of high visibility of gender equity challenges.

Adding to the invisibility of the gender equity problems in the organization, 54\% of the open answers expressed the opinion that nothing or too little was being done to achieve gender equity. A sub-group of people in this category even explicitly expressed doubts that leaders in the organization intended to implement the existing policies. Adding to this observation, the most prominent theme that arose out of the qualitative data was that $24 \%$ of respondents reported that gender equity policies were not being implemented. However, most damaging for visibility was the finding that the average modern sexism score for the university employees were 4.18 , which reveals that many employees are not just blind to gender equity challenges, but also resist initiatives which facilitate gender equity goals.

Our finding of higher than average modern sexism scores, as well as our qualitative findings which suggest gender blindness and perceived reverse discrimination against men, indicate that one of the major challenges to gender equity in this organization is explicit modern sexism. This is consistent with many people not believing that gender discrimination or bias could contribute to the underrepresentation of women at Associate Professor and Professor levels. This means that despite the fact that all Faculties except one have more women at both $\mathrm{PhD}$ and Post-Doctoral levels, but fewer at Associate Professor and Professor levels, many employees considered this a reflection of women's lack of abilities or motivations, rather than an expression of gender-based discrimination. This is important, because Acker (2006) argues that another key component of moving an organization towards greater gender equity is low legitimacy. In other words, not recognizing injustice in an organizational structure will hinder change.

This suggests that this organization is challenged in achieving gender equity on two fronts: (1) there is low visibility of the challenges in the organization and (2) high legitimacy of modern sexist attitudes such as the attitude that the gender differences which are observed are caused by the women themselves.

It is also of note that there was a group of employees who believed that too much was being done to a achieve gender equity. This indicates that there is not just explicit modern sexism in this organization, but also hostile sexist attitudes. However, it is important to underline that not all employees subscribed to these sexist beliefs. In fact, we found significantly different mod- 
ern sexism scores for employees who thought not enough was being done to achieve gender equity, in comparison to people who thought that enough was being done. In this way, our data demonstrates that employees who were very high on explicit sexism thought that current gender equity initiatives were ade-

quate (or even too much in women's favor). The main task of the university at this stage is to convince all their employees that sexism has an effect on gender segregation in the organization; in the hiring, promotions, and the work environment in gener$\mathrm{al}$; and that interventions are therefore necessary and supported by the leaders in the organization.

What kind of interventions might be necessary to create a constructive and progressive work environment where gender equity can be achieved? We suggest that the first task this organization faces is to establish clear and unequivocal communication about their gender equity agenda. Leadership would benefit from being explicit in their recognition that there are problems with gender equity, and that sexist attitudes are not considered legitimate. Challenges to gender equity should be made visible to all employees, and the leader's intended solutions to these challenges would benefit from being made explicit.

Furthermore, employees with lower levels of modern sexism tend to express a clear need to ensure implementation of progressive intentions. To achieve this, several steps are needed. The first is visibility those who are not aware of the problem would benefit from being made aware of it (Becker and Swim 2011; Swim et al. 2004). This step involves making clear to all employees that modern sexism attitudes are in conflict with the organizations perspectives and intentions. This could be achieved by putting in place explicit initiatives to increase awareness of the problem for all employees - not just the ones that are already gender aware - but particularly the leaders in the organization who are responsible for carrying out the organization's policies.

A second possible step is that policies need to be implemented by all leaders in the organization. Gender equity policies should not be voluntary options, but rather concrete action plans with concrete goals that need to be met within a set time frame. Implementation of this could be ensured by holding all leaders accountable for how successful they are at increasing the number of female researchers (particularly at the higher levels), and putting sanctions in place for failure to achieve organizational goals. This is important because accountability facilitates all employees in the belief that policies will in fact be implemented. Key words should be; increased visibility of the gender equity problem, holding leaders accountable to gender equity goals, and sanctions for leaders who do not conform with the organizations goals. Such interventions have the potential to increase the visibility of the problem and help delegitimize sexist attitudes and behaviors in this and similar organizations, making it possible to progress towards gender equity.

\section{CONCLUSION}

Our study clearly shows that perceived gender discrimination and attitudes to gender equity policy are positively related. If one holds modern sexist views then one will not be supportive of gender equity initiatives. People high on modern sexism scores are more likely to believe that enough or even too much is being done to achieve gender equity. In other words, such employees are likely to be blind to the explicit sexism they are contributing to in the organization. When this gender blindness is combined with unclear communication about gender policies and goals, such modern and hostile sexist attitudes are left unchallenged. It is left to employees with low modern sexism attitudes to encourage the organization to 
make gender policies more visible. A positive finding of this study is that the majority of employees sampled already do share the gender equity visions of the university. The take home message of this comprehensive study is therefore that until gender inequality is approached as an organizational issue which should be solved at an organizational level - rather than an individual issue which can be solved at an individual level - gender equity cannot be achieved.

\section{REFERENCES}

- Acker, J. 1990. Hierarchies, jobs, bodies: A theory of gendered organizations. Gender and Society. 4, 139-158. DOI:

https://doi.org/10.1177/089124390004002002 - Acker, J. 2006. Inequality Regimes: Gender, class, and race in organizations. Gender and Society. 20(4), 441-464. DOI:

https://doi.org/10.1177/0891243206289499

- Becker, J. C. and Swim, J. K. 2011. Seeing the

Unseen: Attention to Daily Encounters With Sexism as Way to Reduce Sexist Beliefs. Psychology of Women Quarterly. 32(2), 227-247. DOI: https://doi.org/10.1177/0361684310397509 - Cambell, B., Schellenberg, E. G. and Senn, C. Y. 1997. Evaluating measures of Contemporary Sexism. Psychology of Women Quarterly. DOI: https://doi.org/10.1111/j.1471-

6402.1997.tb00102.x

. Carli, L. L., Alawa, L., Lee, Y., Zhao, B. and Kim, E. 2016. Stereotypes About Gender and Science: Women $\neq$ Scientitsts. Psychology of Women Quarterly. 40(2), 244-260. DOI: https://doi.org/10.1177/0361684315622645 - Charles, M. and Grusky, D. B. 2004. Occupational Ghettos. Standford: Standford University Press.

. Creswell, J. W., and Plano Clark, V. L. 2007. Designing and Conducting Mixed Methods Research. Thousand Oaks: SAGE. DOI: https://doi.org/10.1177/1094428108318066 - Ekehammer, B., Akrami, N. and Araya, T. 2000. Development and validation of Swedish classical and modern sexism scales. Scandinavia Journal of Psychology. 41, 307-314.

- Glaser, B.G. and Strauss, A. 1967. The Discovery of Grounded Theory. Strategies for Qualitative Research. Chicago, IL: Aldine Publishing Company.
. Glick, P. and Fiske, S. T. 1996. The Ambivalent Sexism Inventory: Differentiating hostile and benevolent sexism. Journal of Personality and Social Psychology. 70, 491-512.

. Glick, P. and Fiske, S. T. 1997. Hostile and benevolent sexism. Psychology of Women Quarterly. 21, 119-135. DOI:

https://doi.org/10.1111/j.1471-

6402.1997.tb00104.x

. Glick, P. and Fiske, S. T. 2001. An ambivalent alliance. American Psychologist. 56(2), 109-118.

- Heilman, M. E. 1983. Sex bias in work settings: The Lack of Fit model. Research in Organizational Behaviour. 5, 269-298.

- Heilman, M. E. 2012. Gender Stereotypes and Workplace Bias. Research in Organizational Behavior. 32, 113-135. DOI:

https://doi.org/10.1016/j.riob.2012.11.003

· Henningsen, I. and Højgaard, L. 2002. "The

Leaking Pipeline” - øjebliksbilleder af kønnede inog eksklusionsprocesser i Akademia. Dansk Sociologi. 13(2). 216-227. DOI:

http://dx.doi.org/10.1177/0146167202239047

- Huffman, M. L., Cohen, P. N., and Pearlman, J. 2010. Engendering Change: Organizational Dynamics and Workplace Gender Desegregation, 1975-2005. Administrative Science Quarterly. 55(2), 255-277. DOI:

https://doi.org/10.2189/asqu.2010.55.2.255

- Ministery of Employment in DK. 2010. Kvinder og mend på arbejdsmarkedet 2010. [Online].

[Accessed 26 April 2019]. Available from: https://www.eurofound.europa.eu/publications/article/2011/women-and-men-in-the-danish-labour-market

- Morrison, M. A., Morrison, T. G., Pope, G. A., and Zumbo, B. D. 1999. An Investigation of Measures of Modern and Old-Fashioned Sexism. Social Indicators Research. 48(1), 39-49. DOI: http://dx.doi.org/10.1023/A:1006873203349 - Moss-Racusin, C. A., Dovidio, J. F., Brescoll, V. L., Graham, M. J., and Handelsman, J. 2012. Science Faculty s Subtle Gender Biases favor Male Students. PNAS. 109(41), 16474-16479. DOI: https://doi.org/10.1073/pnas.1211286109 - Morton, T. A., Postmes, T., Haslam, S. A., and Hornsey, M. J. 2009. Theorizing Gender in the Face of Social Change: Is There Anything Essential about Essentialism? Journal of Personality and Social Psychology. 96(3), 653-664. DOI: https://doi.org/10.1037/a0012966 - Rudman, L. A. and Glick, P. 2008. The Social Psychology of Gender - How Power and Intimacy Shape Gender Relations. NY: Guilford.

- Sakalli-Urgurlu, N. 2009. Ambivalent Sexism, 
gender, and major as predictors of Turkish college student's attitudes towards women and men's atypical educational choices. Sex Roles. 62, 427437.

- Sibley, C. G. and Perry, R. 2010. An opposing process model of benevolent sexism. Sex Roles. 62, $438-452$.

. Skewes, L., Fine, C., and Haslam, N. 2018. Beyond Mars and Venus: The Role of Gender Essentialism in Support for Gender Inequality and Backlash. PLOS One. 13(7): e0200921. DOI: https://doi.org/10.1371/journal.pone.0200921 - Strauss, A. and Corbin, J. 1990, Basic Qualitative Research: Grounded Theory Procedures and Techniques. Newbury Park, CA: Sage Publications. . Swim, J. K., Aikin, K. J., Hall, W. S., and Hunter, B. A. 1995. Sexism and Racism: Old-Fashioned and Modern Prejudices. Journal of Personality and Social Psychology. 68(2), 199-214. DOI: http://dx.doi.org/10.1037/0022-

3514.68.2.199

. Swim, J. K., Mallett, R., and Stangor, C. 2004. Understanding Subtle Sexism: Detection and Use of Sexist Language. Sex Roles. 51 (3/4). DOI: https://doi.org/10.1023/B:SERS.0000037757. 73192.06

. Van Wijk, C. H. 2011. Contemporary Sexism in the South African Navy. Soc Indic Res. 299-311.

- Venables, W. N. and Ripley, B. D. 2002. Modern Applied Statistics with $S$. Fourth Edition. New York: Springer.

\section{APPENDIX}

\section{Modern Sexism Scale}

(Swim et al. 1995)

[Question 1 and 6 is always adapted to the country the questionnaire is carried out in.] Below are some statements. To what extent do you agree with these statements? Please answer on a scale from 1 = completely disagree to $7=$ completely agree

1. Discrimination against women is no longer a problem in Denmark

2. Women often miss out on good jobs due to sexual discrimination

3 . It is rare to see women treated in a sexist manner on television

4. On average, people in our society treat men and women equally

5. Society has reached the point where women and men have equal opportunities for achievement

6. It is easy to understand the anger of feminists in Denmark

7. It is easy to understand why feminists are still concerned about societal limitations of women's opportunities

8. Over the past few years, the government and the news media have been showing more concern about the treatment of women than is warranted by women's actual experiences 